University of Wollongong

Research Online

Australian Institute for Innovative Materials -

Papers

Australian Institute for Innovative Materials

$1-1-2013$

Electrically conductive coatings of nickel and polypyrrole/poly(2methoxyaniline-5-sulfonic acid) on nylon Lycra® textiles

B C. Kim

Dongguk University

P C. Innis

University of Wollongong, innis@uow.edu.au

Gordon G. Wallace

University of Wollongong, gwallace@uow.edu.au

C T.J Low

University of Southampton

F C. Walsh

University of Southhampton

See next page for additional authors

Follow this and additional works at: https://ro.uow.edu.au/aiimpapers

Part of the Engineering Commons, and the Physical Sciences and Mathematics Commons

Research Online is the open access institutional repository for the University of Wollongong. For further information contact the UOW Library: research-pubs@uow.edu.au 


\title{
Electrically conductive coatings of nickel and polypyrrole/poly(2- methoxyaniline-5-sulfonic acid) on nylon Lycra® textiles
}

\begin{abstract}
Woven nylon Lycra ${ }^{\circledR}$ has been coated with finely-divided electroless nickel-phosphorus, polypyrrole and electroless nickel/polypyrrole to produce flexible and electrically conductive textiles. The coated textiles were tested for their electrochemical activity, electrical resistivity and resistivity in response to mechanical strain. Pre-dyeing the textile with poly(2-methoxyaniline-5-sulfonic acid) (PMAS) prior to electroless metallization by electroless nickel and via chemical polymerization of polypyrrole was found to be beneficial in enhancing the resultant coating as well as stabilizing surface resistance responses when exposed to a wide range of strain. The mass gain due to the nickel coating was found to increase linearly with deposition time. The surface resistivity of the coated textile was found to decrease at longer nickel deposition times.
\end{abstract}

\section{Keywords}

sulfonic, acid, coatings, nylon, poly, lycra, textiles, 2, conductive, electrically, methoxyaniline, nickel, 5, polypyrrole

\section{Disciplines}

Engineering | Physical Sciences and Mathematics

\section{Publication Details}

Kim, B. C., Innis, P. C., Wallace, G. G., Low, C. T.J., Walsh, F. C., Cho, W. J. \& Yu, K. H. (2013). Electrically conductive coatings of nickel and polypyrrole/poly(2- methoxyaniline-5-sulfonic acid) on nylon Lycra® textiles. Progress in Organic Coatings, 76 (10), 1296-1301.

\section{Authors}

B C. Kim, P C. Innis, Gordon G. Wallace, C T.J Low, F C. Walsh, W J. Cho, and K H. Yu 


\title{
Electrically conductive coatings of nickel and polypyrrole/poly(2- methoxyaniline-5-sulfonic acid) on nylon Lycra ${ }^{\circledR}$ textiles
}

\author{
B.C. Kim ${ }^{\mathrm{c}}$, P.C. Innis ${ }^{\mathrm{a}^{*}}$, G.G. Wallace ${ }^{\mathrm{a}}$, C.T.J. Low ${ }^{\mathrm{b}}$, F.C. Walsh ${ }^{\mathrm{b}}$, K.H.Yu ${ }^{\mathrm{c}}$ \\ ${ }^{\mathrm{a}}$ ARC Centre for Electromaterials Science \& Intelligent Polymer Research Institute, \\ Innovation Campus, University of Wollongong, Squires Way, Fairy Meadow, NSW 2519, \\ Australia. \\ ${ }^{b}$ Electrochemical Engineering Laboratory, national Centre for Advanced Tribology at \\ Southampton, School of Engineering Sciences, University of Southampton, Highfield, \\ Southampton SO17 1BJ, United Kingdom. \\ 'Department of Chemistry, University of Dongguk-Seoul, 30, Pil-Dong-ro, 1-gil, Jung-gu, \\ Seoul, 100-715, Korea
}

*Author for correspondence; innis@uow.edu.au

\begin{abstract}
Woven nylon Lycra ${ }^{\circledR}$ has been coated with finely-divided electroless nickel-phosphorus, polypyrrole and electroless nickel/polypyrrole to produce flexible and electrically conductive textiles. The coated textiles were tested for their electrochemical activity, electrical resistivity and resistivity in response to mechanical strain. Pre-dyeing the textile with poly(2methoxyaniline-5-sulfonic acid) (PMAS) prior to electroless metallization by electroless nickel and via chemical polymerization of polypyrrole was found to be beneficial in enhancing the resultant coating as well as stabilising surface resistance responses when exposed to a wide range of strain. The mass gain due to the nickel coating was found to increase linearly with deposition time. The surface resistivity of the coated textile was found to decrease at longer nickel deposition times.
\end{abstract}

Keywords: conductive polymer, electroless nickel-phosphorus, metallization, organic dye, poly(2-methoxyaniline-5-sulfonic acid), polypyrrole, textile. 


\section{Introduction}

Recent years have seen increasing interest in the coating of electrically conductive materials onto non-conductive textiles. Such conductive coatings include metals, alloys and/or conducting polymers. The textiles are typically woven cotton, linen, polyester and nylon. Such coatings are highly flexible and have many demonstrated applications such as antibacterial fabrics, wearable sensors in biomechanical monitoring and protective clothing for electromagnetic shielding. [1-5]. The focus of recent developments has been to identify coatings having improved characteristics, such as enhanced electrical-strain sensitivity, longterm stability and electrical conductivity of the coated textiles. In this work, we report the synthesis and characterizations of electrically conductive coatings onto nylon Lycra ${ }^{\circledR}$. Lycra ${ }^{\circledR}$ is a synthetic eleastomeric polymer. Its macromolecular structure is made up of repeating units denoted by the $\mathrm{x}$ and $\mathrm{n}$ next to the parentheses in the structure, see Figure 1 . Lycra ${ }^{\circledR}$ has a stretchy section that make it soft and rubbery, and a rigid section that makes it tough. In Figure $1, \mathrm{n}$ is a very large number of repeating double 'molecular segments' in the polymer chain; while $\mathrm{x}$ is the variable number of units in the 'elastic' molecular segment which gives differing degrees of 'stretchiness'. The conductive materials are an electroless nickel deposit, a conductive polypyrrole coating deposited by chemical oxidation and a pre-synthesized poly(2-methoxyaniline-5-sulfonic acid) [6,7] (PMAS) as an adsorbed dye that was both electroactive and electrically conducting. The electrochemical activity, electrical resistivity and strain performance of three combinations of coating conductive materials on the textile are considered.

\section{Experimental details}

Figure 2 shows the three coating combinations used to produce the metalized surfaces on the textile. The combinations were (a): a nickel deposit on nylon Lycra ${ }^{\circledR}$ (Ni/Ny), (b) a nickel deposit on polypyrrole coating on nylon Lycra ${ }^{\circledR}$ (Ni/Py/Ny) and (c) a nickel deposit on 
polypyrrole coating on polypyrrole/poly(2-methoxyaniline-5-sulfonic acid) adsorbent dye on nylon Lycra ${ }^{\circledR}$ (Ni/Py/PMAS/Ny). The nickel deposits were produced via electroless nickel deposition and the polypyrrole coating via a chemical polymerization route. The as-deposited textiles were tested for (a) electrical resistivity, (b) strain performance (c) electrochemical response to the ferrocyanide/ferricyanide (hexacyanoferrate (II)/hexacyanoferrate (III)) redox couple in an aqueous potassium chloride electrolyte.

\subsection{Electroless nickel deposition on textile}

Electroless nickel-phosphorus deposition onto the textile was carried out at $70{ }^{\circ} \mathrm{C}$ for various deposition times ranging from 1 to 120 minutes in an electrolyte (volume: $200 \mathrm{~mL}$ ) containing $20 \mathrm{~g} \mathrm{dm}^{-3} \mathrm{NiSO}_{4} \cdot 6 \mathrm{H}_{2} \mathrm{O}, 35 \mathrm{~g} \mathrm{dm}^{-3} \mathrm{NH}_{4} \mathrm{Cl}, 10 \mathrm{~g} \mathrm{dm}^{-3}$ Sodium Citrate and $20 \mathrm{~g} \mathrm{dm}^{-3}$ $\mathrm{NaPO}_{2} \mathrm{H}_{2}$ [8-12]. Prior to the deposition, the nylon Lycra ${ }^{\circledR}$ was cleaned in $20 \mathrm{~g} \mathrm{dm}^{-3} \mathrm{NaBH}_{4}$ for 2 minutes at $22{ }^{\circ} \mathrm{C}$. Then it was washed with copious amount of water for 2 minutes. It was then soaked in $0.1 \mathrm{~g} \mathrm{dm}^{-3} \mathrm{PdCl}_{2}$ and $10 \mathrm{ml} \mathrm{dm}^{-3} \mathrm{HCl}$ for 2 minutes at $22{ }^{\circ} \mathrm{C}$ to provide an active surface for electroless nickel deposition. The above procedures were also used for the deposition of nickel onto polypyrrole coated textiles. At open-circuit, nickel was deposited onto catalytically active surface; while at the same time, hypophosphite ion get oxidizes to form orthophosphite ion as follows in scheme 1:

$$
\mathrm{Ni}^{2+}+\mathrm{H}_{2} \mathrm{PO}_{2}^{-}+2 \mathrm{H}_{2} \mathrm{O} \rightarrow \mathrm{Ni}+\mathrm{H}_{2} \mathrm{PO}_{3}^{-}+2 \mathrm{H}^{+}
$$

\subsection{Dyeing of the textile with PMAS}

3 g of nylon Lycra ${ }^{\circledR}$ was soaked in a solution containing $0.3 \%(\mathrm{w} / \mathrm{v})$ PMAS prepared via a previously reported method [6]. The dyeing of the textile was carried out under stirred conditions via a magnetic stirrer, c.a. $600 \mathrm{rpm}$ in a $300 \mathrm{~mL}$ solution. The temperature of the 
solution was controlled at $90{ }^{\circ} \mathrm{C}$ and the textile was soaked for 4 hours. After that, it was washed with copious amounts of water then dried in air to have a green appearance.

\subsection{Chemical polymerization of polypyrrole onto nylon Lycra}

3 g of nylon Lycra ${ }^{\circledR}$ either uncoated or dyed by PMAS was immersed in a solution (volume: $100 \mathrm{~mL}$ ) of $0.02 \mathrm{~mol} \mathrm{dm}^{-3} \mathrm{FeCl}_{3}$ for 20 minutes. Equal volumes $(100 \mathrm{~mL})$ of 0.02 mol dm${ }^{-3}$ Salicylic acid (SSA) and $0.003 \mathrm{~mol} \mathrm{dm}^{-3}$ Anthraquinone-2-sulfonic acid (AQSA) were then added into this solution $[13,14]$. The mixture was stirred for 10 minutes then poured into a $100 \mathrm{~mL}$ solution of $0.009 \mathrm{~mol} \mathrm{dm}^{-3}$ Pyrrole monomer solution. Chemical polymerization of polypyrrole was carried out at $22{ }^{\circ} \mathrm{C}$ under stirred conditions via a magnetic stirrer rotating at about $200 \mathrm{rpm}$. The polymerization process lasted for 210 minutes. After that, the polypyrrole coated textile was washed with copious amount of water then dried in air at $22{ }^{\circ} \mathrm{C}$. Nylon Lycra ${ }^{\circledR}$ without the PMAS dyeing step was also coated by polypyrrole using the same procedure as above. The reaction and deposition of polypyrrole is shown in the reaction scheme .2

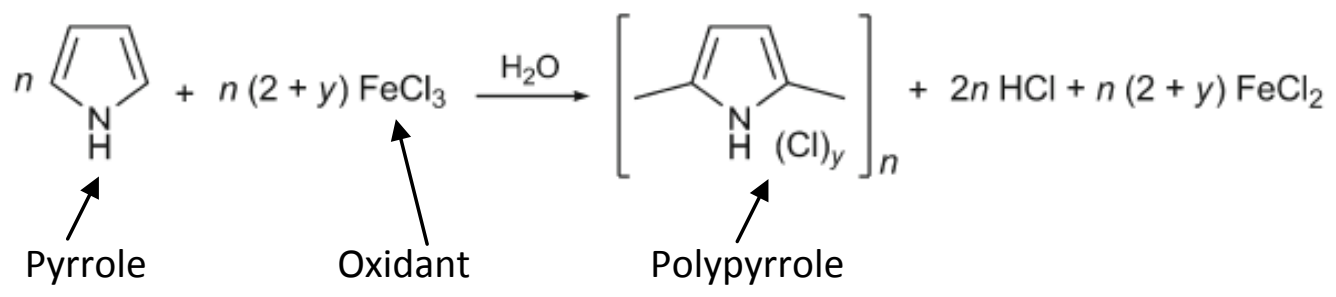

\subsection{Electrical resistivity measurements}

Conductivity of the coated textiles was measured using a custom made four-electrode probe. Two gold electrodes (surface area: $0.4 \mathrm{~cm}^{2}$, thickness: $0.05 \mathrm{~cm}$ ) were used as the contact backplate. The inter-electrodes spacing was approximately $2 \mathrm{~mm}$. All the surface 
resistance measurements were carried out at room temperature, $22{ }^{\circ} \mathrm{C}$ via PAR363 Galvanostat (supplier: EG\&G Princeton Applied Research, USA) and a digital multimeter. A $1 \mathrm{~kg}$ weight was used to compress the samples during measurement.

\subsection{Electrochemical response measurements}

Cyclic voltammetry was carried out on the coated textiles in an electrolyte containing $1.0 \mathrm{~mol} \mathrm{dm}{ }^{-3} \mathrm{KCl}$ and $0.01 \mathrm{~mol} \mathrm{dm}^{-3} \mathrm{~K}_{4} \mathrm{Fe}(\mathrm{CN})_{6}$ at room temperature, $22{ }^{\circ} \mathrm{C}$. A glass, threeelectrode electrochemical cell was used. The working electrode was the coated textile (thickness: $1 \mathrm{~mm}$, length: $30 \mathrm{~mm}$ and width: $0.5 \mathrm{~mm}$ ). The counter electrode was a reticulated 100 pores per inch vitreous carbon (ERG Aerospace), providing an electrode 300 x 100 x 100 $\mathrm{mm}$ in size. The electrode potential was measured against $\mathrm{Ag} \mid \mathrm{AgCl}\left(3.0 \mathrm{~mol} \mathrm{dm}{ }^{-3} \mathrm{NaCl}\right)$ reference electrode. The working electrode potential was swept between $-0.4 \mathrm{~V}$ to $+1.2 \mathrm{~V} v s$. $\mathrm{Ag} \mid \mathrm{AgCl}$ at a potential sweep rate $50 \mathrm{mV} \mathrm{s}^{-1}$. All electrochemical measurements were performed using an AD Instruments potentiostat.

\subsection{Strain performance measurements}

The strain performance of the Ni only, Ni/Py and Ni/Py/PMAS coated textiles was measured using an Animatics linear actuator (VLCT55) capable of a maximum strain rate of $1000 \mathrm{~mm} \mathrm{~s}^{-1}$. The textiles (length: $40 \mathrm{~mm}$ and width: $10 \mathrm{~mm}$ ) were subjected to increasing (stretch) and decreasing (relaxation) sinusoidal response from $10 \%$ to $70 \%$ strain at a sinusoidal frequency of $1 \mathrm{~Hz}$. The peak resistance of the textiles was obtained at the strain cycle maximum. An averaged value was taken over 20 to 25 cycles.

\section{Results and Discussion}

\subsection{Surface Characterization of Coated Nylon Lycra ${ }^{\circledR}$}


FTIR analysis was performed using a Shimadzu AIM 8800 FTIR microscope at an image aperture of 150 x 150um at a $16 \mathrm{~cm}^{-1}$ resolution, Figure 3. Significantly, incomplete coating of the nylon Lycra ${ }^{\circledR}$ textile substrate by the polypyrrole (Py/Ny) was observed as spectral components of both the substrate and polypyrrole coating being evident. Contrasting this observation was the PMAS pre-dyed nylon Lycra ${ }^{\circledR}$ substrate, which was subsequently coated with polypyrrole (Py/PMAS/Ny), which exhibited a strong response almost nylon Lycra $^{\circledR}$ substrate free spectra of the conducting polymer over-coating.

Figure 4(a) and (b) show images of the uncoated nylon Lycra ${ }^{\circledR}$ substrate. The textile had a porous structure consisting of threads twisted in a single direction. The thread diameter was c.a. 15 to $20 \mu \mathrm{m}$. Figures 4(c) to (d) shows the development in surface microstructure of nickel coated nylon Lycra ${ }^{\circledR}$ textile. The electroless nickel was deposited on the surface of the textile as finely divided particulates. The electroless nickel deposits were typically 1 to $5 \mu \mathrm{m}$ in size and had an irregular shape. As expected, a larger mass of nickel deposit was found on the textile surface at longer electroless nickel deposition times in Figure 4(e). The electroless nickel deposit mass was larger and the textile appeared more roughened at longer nickel deposition times. Figure 5 shows the surface microstructure of polypyrrole coated textiles prepared with or without an undercoat of PMAS adsorbent dye. The presence of these two components allowed the deposition of a larger mass of nickel on the surface of the textile. The nickel deposits appeared to fill in the spaces between adjacent threads as the coatings became thicker and rougher.

\subsection{Weight Gain by Coated Nylon Lycra ${ }^{\circledR}$}

Figure 6 shows the weight gain by the textile as a function of electroless nickel deposition time. All three coating combinations used to produce the metalized surfaces on the 
textile showed a similar weight gain response. It was found that the rate of weight gain increased linearly with the deposition time. The presence of undercoats of polypyrrole and/or PMAS on the textile had led to a faster growth rate for nickel. The highest growth rate, c.a. $390 \mathrm{mg}$ minute $^{-1}$ was achieved for a textile having an electroless nickel deposit on a polypyrrole coating on the adsorbed PMAS dye on nylon Lycra ${ }^{\circledR}$ (Ni/Py/PMAS/Ny).

\subsection{Electrical Resistivity of Coated Nylon Lycra ${ }^{\circledR}$}

Figure 7 shows the surface resistivity of the coated textiles decreased sharply after a 10 minutes deposition time, e.g. from several hundreds of ohms at 1 minute to several hundreds of milliohms at 30 minutes. This observation is consistent with the literature [15-17] in which increasing the deposition time, hence the mass, of nickel on the textile surface allowed a better electrical contact within the matrix of the textile. It was also found that the surface resistance of the coated textile was lowest in a coating containing undercoats of polypyrrole and PMAS. This observation was anticipated because the presence of PMAS as an adsorbent dye on the bare substrate provided a more active surface for the initiation of polypyrrole deposition, as evidenced by the FTIR analysis in Figure 3. Consequently, this led to an improved deposition of nickel on the polypyrrole surface, which was consistent with the findings in Figures 5 and 6.

\subsection{Strain Performance of Coated Nylon Lycra ${ }^{\circledR}$}

Prior studies have shown that conducting polymer textile coatings have a high degree of resilience to mechanical stretching $[1,3,4,7]$. Figure 8 shows the normalized change in the surface resistivity of the Ni polymer coated textiles as a function of strain force (Ni deposition time $=30 \mathrm{~min})$. An approximately linear resistance vs. strain behavior of the coated textiles was recorded. The use of PMAS as absorbent dye drastically reduced changes in the surface resistance of the textiles over a wide range of strain force, from 10 to $70 \%$. For example, in 
the absence of a PMAS undercoat, the textile displayed a $50 \%$ change in its resistance at $70 \%$ strain; however, only $15 \%$ change in resistance was recorded in a textile containing PMAS. This behaviour shows that a textile containing nickel-polypyrrole/poly(2methoxyaniline-5-sulfonic acid) was effective as a textile strain gauge in which the electrical resistance decreased as the conductive textile is stretched $[18,19]$. This was due to the better deposition of polypyrrole promoted by a PMAS undercoat on Nylon Lycra. Contrasting this observation, the Ni coating on the uncoated Nylon Lycra failed to produce repeatable test results due to very poor adhesion of the $\mathrm{Ni}$ on the surface of textile over repeated contraction and expansion processes associated with the strain tests.

\subsection{Electrochemical Response of Coated Nylon Lycra ${ }^{\circledR}$}

Figure 9 shows the cyclic voltammograms recorded for all three coating combinations used to produce the metalized surfaces on the textile. It was found that the electrochemical activity of ferrocyanide/ferricyanide was most active on the surface of a textile containing undercoats of polypyrrole and PMAS. For this coated textile, a single oxidation and reduction peak were observed corresponds to the redox couple of ferrocyanide/ferricyanide [20-22]. For textiles containing no polymethoxysulfonate adsorbent dye, the magnitude of the recorded current was much lower and no clear peaks were observed.

\section{Conclusions}

Electrically conductive coatings have been deposited onto a nylon Lycra ${ }^{\circledR}$ surface to improve its electrical conductivity and electrochemical activity. The conductive materials were finely divided, electroless nickel particles or a continuous polypyrrole film. Pre-dyeing the textile with poly(2-methoxyaniline-5-sulfonic acid) prior to metallization of the nickel then chemical polymerization of a polypyrrole coating significantly improved the surface and 
coating properties. The use of a pre-adsorbed poly(2-methoxyaniline-5-sulfonic acid) dye significantly reduced changes in the surface resistance of the textiles over a wide range of strain force, from 10 to $70 \%$. An approximately linear resistance vs. strain behavior of the coated textiles was recorded. The presence of poly(2-methoxyaniline-5-sulfonic acid) on the textile surface also allowed the deposition of a larger amount of conductive material. As expected, increasing the mass of nickel and polypyrrole deposited on the surface of the textiles enhanced electrical conductivity by several orders of magnitude and increased electrochemical activity for the ferrocyanide/ferricyanide ion redox couple.

\section{Acknowledgements}

The authors gratefully acknowledge funding received from the National Health and Medical Research Council (NHMRC), Australia and the Research Institute for Industry (RIfI) at the University of Southampton, United Kingdom.

\section{References}

[1] B.J. Munro, T.E. Campbell, G.G. Wallace and J.R. Steele, Sensors and Actuators B: Chemical, 131 (2008) 541.

[2] A. Bhattacharya, A. De, Prog. Solid St. Chem., 24 (1996) 141.

[3] J. Wu, D. Zhou, C.O. Too, G.G. Wallace, Synthetic Metals, 155 (2005) 698.

[4] M. in het Panhuis, J. Wu, S.A. Ashraf, G. G. Wallace, Synthetic Metals, 157 (2007) 358.

[5] M. Mičušík, T. Nedelčev, M. Omastová, I. Krupa, K. Olejníková, P. Fedorko, M.M. Chehimi, Synthetic Metals, 157 (2007) 914.

[6] F. Masdarolomoor, P.C. Innis, S. Ashraf, G.G. Wallace, Synthetic Metals, 153 (2005) 181.

[7] G.G. Wallace, T.E. Campbell, P.C. Innis, Fibers and Polymers 8 (2007) 135.[8] C. Kerr, F.C. Walsh, "Electroless Deposition of Metals", Transactions of the Institute of Metal Finishing, 79 (2001) 41. 
[8] C. Ponce-de-León, C. Kerr, F.C. Walsh, "Electroless Plating for Protection against Wear”, in B.G. Mellor (Ed) Surface Coatings for Protection against Wear, Woodhead, Cambridge, (2006) 184.

[10] W. Riedel, Electroless Nickel Plating, Finishing Publications Ltd, (1991) Stevenage, Hertfordshire.

[11] A. Brenner, Metal Finishing, 52 (1954) 68.

[12] G.G. Gawrilov, Chemical (Electroless) Nickel Plating, Portcullis Press, Redhill, Surrey, (1979).

[13] L. Wang, X. Li, Y. Yang, Reactive \& Functional Polymers, 47 (2001) 125.

[14] S. Sadki, P. Schottland, N. Brodiec, G. Sabouraud, Chem. Soc. Rev 29, (2000) 283.

[15] E. Gasana, P. Westbroek, J. Hakuzimana, K. De Clerck, G. Priniotakis, P. Kiekens, D. Tseles, Surface \& Coatings Technology, 201 (2006) 3547.

[16] D. Akbarov, B. Baymuratov, R. Akbarov, P. Westbroek, K. De Clerck, P. Kiekens, Text. Res. J., 75 (2005) 197.

[17] F.M. Kelly, J.H. Johnston, T. Borrmann, M.J. Richardson, Eur. J. Inorg. Chem., (2007) 5571.

[18] D. De Rossi, A. Della Santa, A. Mazzoldi, Mater. Sci. Eng., C7 (1999) 31.

[19] J. Wua, D. Zhou, M.G. Looney, P.J. Waters, G.G. Wallace, C.O. Too, Synthetic Metals 159 (2009) 1135.

[20] D. Pletcher, 'A First Course in “Electrode Processes”; The Electrochemical Consultancy, Romsey, 1991.

[21] A.J. Bard, L.R. Faulkner: 'Electrochemical Methods: Fundamentals and Applications', 2nd edn; (2001), Chichester, Wiley.

[22] F.C. Walsh, A First Course in Electrochemical Engineering, The Electrochemical Consultancy, Romsey, (1993). 
Figure 1 Molecular structure of Lycra ${ }^{\circledR}$.

Figure 2 Strategies used to realize the synthesis of conductive coatings on textiles. Type (a) electroless nickel deposit on nylon Lycra $^{\circledR}$ (Ni/Ny), (b) electroless nickel deposit on polypyrrole coated nylon Lycra ${ }^{\circledR}$ (Ni/Py/Ny) and (c) electroless nickel deposit on polypyrrole coated nylon Lycra ${ }^{\circledR}$ having a preadsorbed poly(2-methoxyaniline-5-sulfonic acid) dye (Ni/Py/PMAS/Ny).

Figure 3 FITR spectra of uncoated nylon Lycra $^{\circledR}(\mathrm{Ny})$, nylon Lycra ${ }^{\circledR}$ coated with polypyrrole (Py/Ny) and nylon Lycra ${ }^{\circledR}$ pre-dyed with poly(2-methoxyaniline5-sulfonic acid) and subsequently coated with polypyrrole (Py/PMAS/Ny).

Figure 4 Surface microstructure showing the development of electroless nickel deposits on a nylon Lycra $^{\circledR}$ textile at controlled deposition times. (a) and (b) as-received, nylon Lycra ${ }^{\circledR}$; (c) 1 minute-; (d) 15 minutes- and (e) 30 minutes of electroless nickel deposition.

Figure 5 Surface microstructure of polypyrrole coated textiles prepared (a) without PMAS and (b) with PMAS undercoat.

Figure $6 \quad$ Weight gain by the textiles as a function of electroless nickel deposition time.

Figure 7 Surface resistivity of the textiles as a function of electroless nickel deposition time.

Figure 8 Normalized change in the surface resistivity of the textiles as a function of strain experienced by the textiles.

Figure 9 Cyclic voltammograms recorded on the textiles in an electrolyte containing $1.0 \mathrm{~mol} \mathrm{dm}^{-3} \mathrm{KCl}$ and $0.01 \mathrm{~mol} \mathrm{dm}^{-3} \mathrm{~K}_{4} \mathrm{Fe}(\mathrm{CN})_{6}$. The potential was swept at $50 \mathrm{mV} \mathrm{s}^{-1}$ between $-0.4 \mathrm{~V}$ and $+1.2 \mathrm{~V}$ vs. Ag|AgCl. 


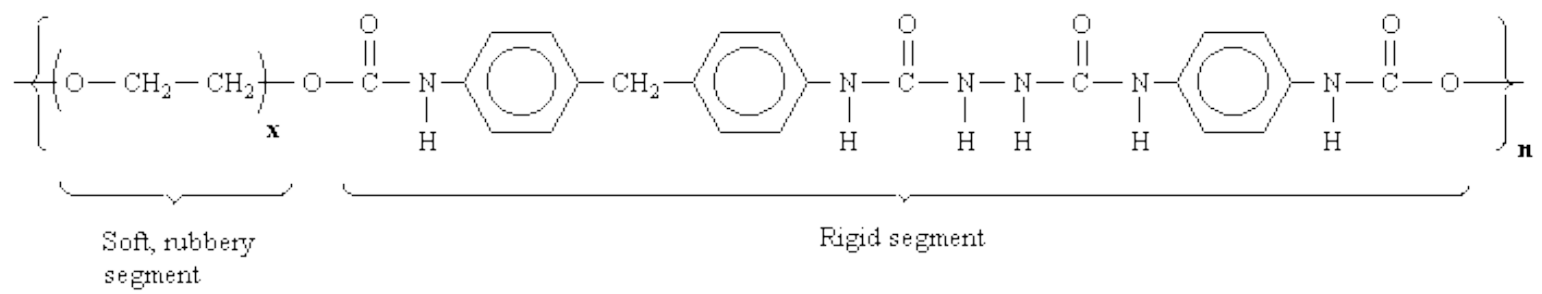

Figure 1 


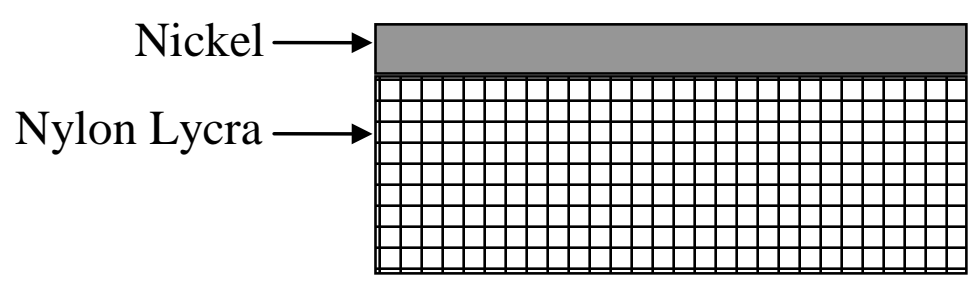

(a)

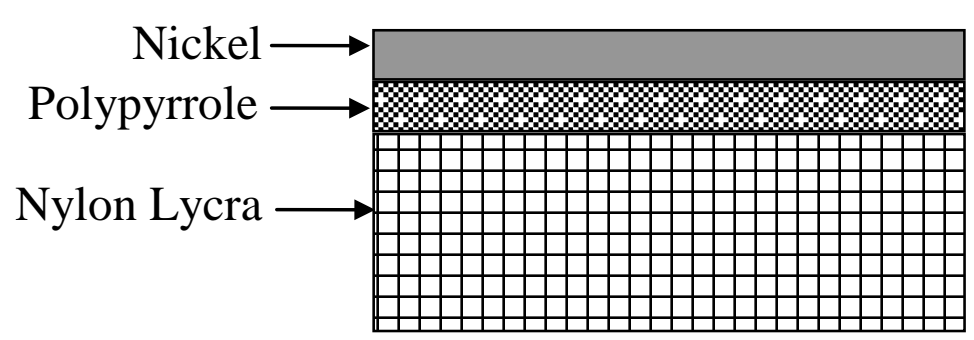

(b)

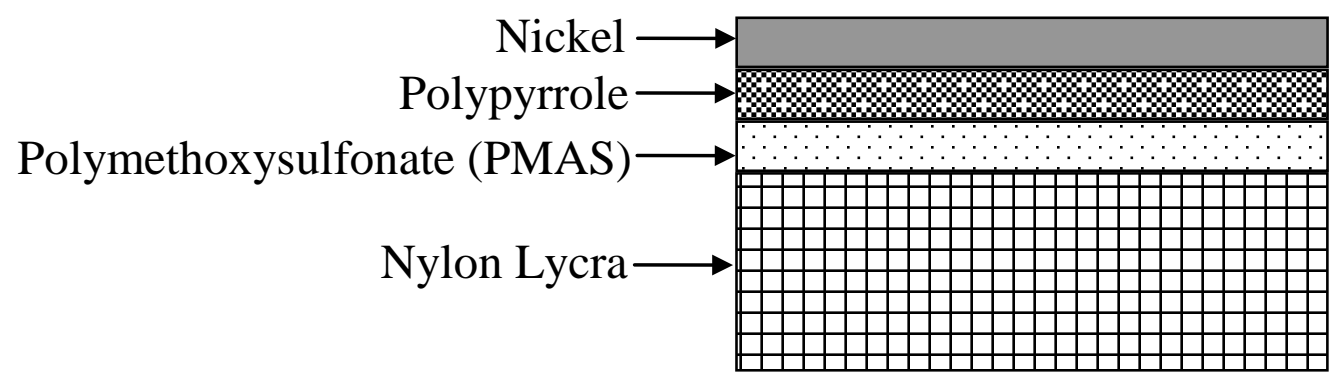

(c)

Figure 2 


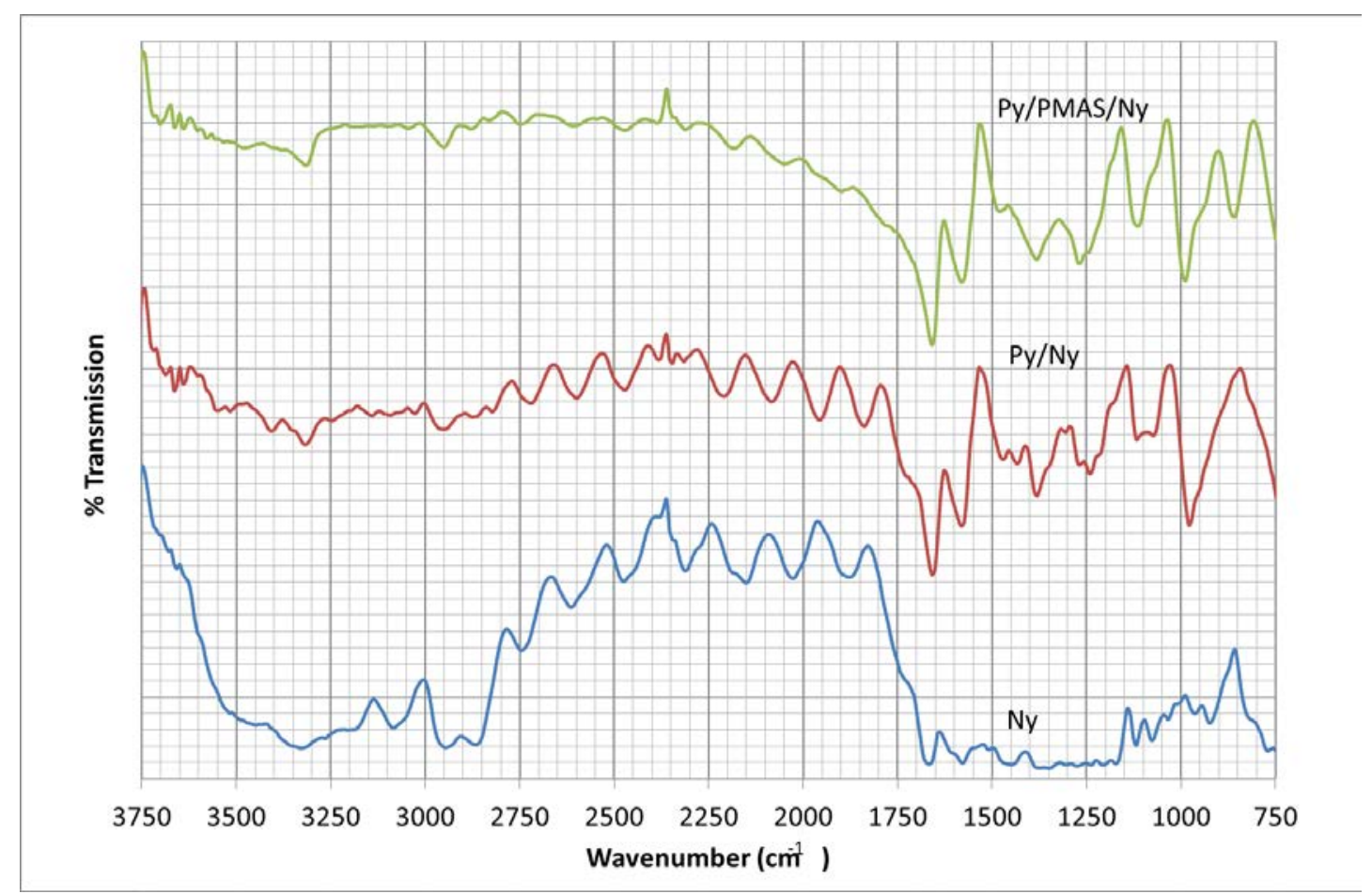

Figure 3 


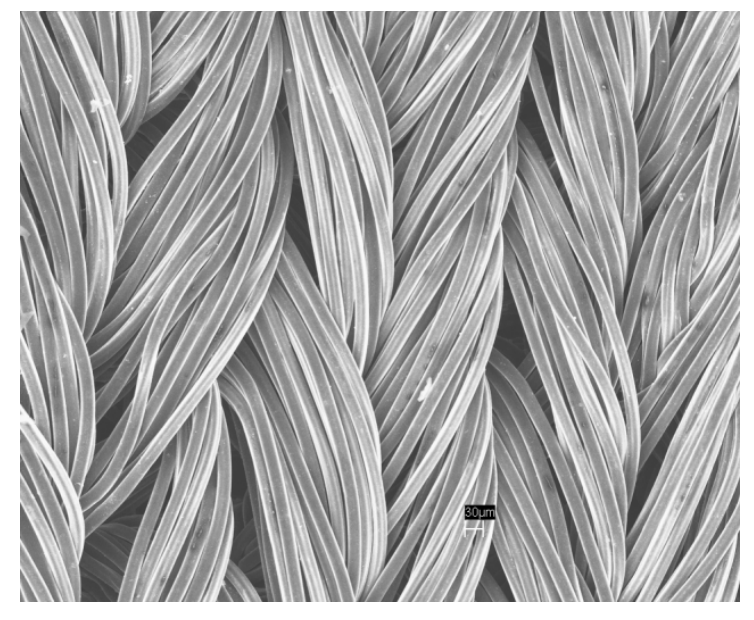

(a)
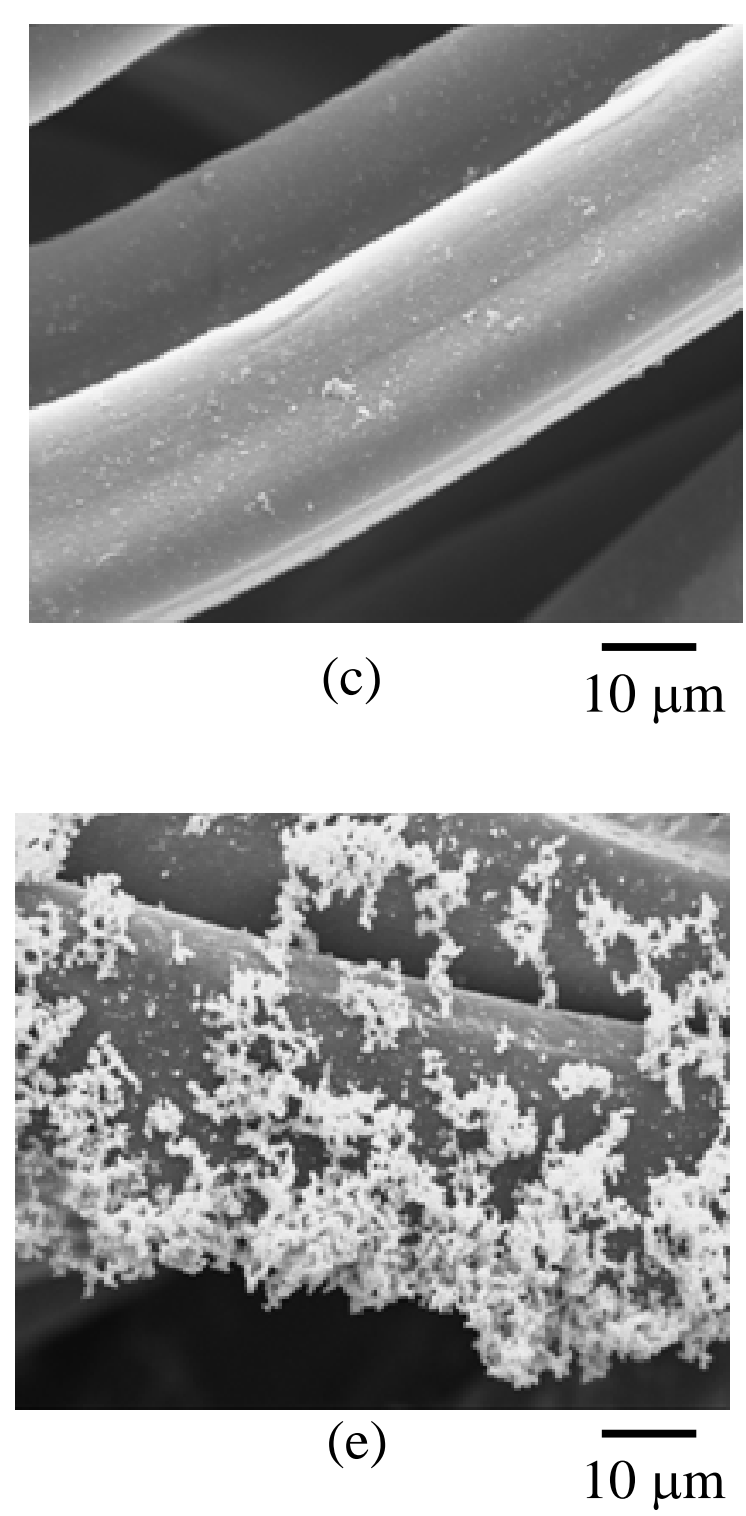
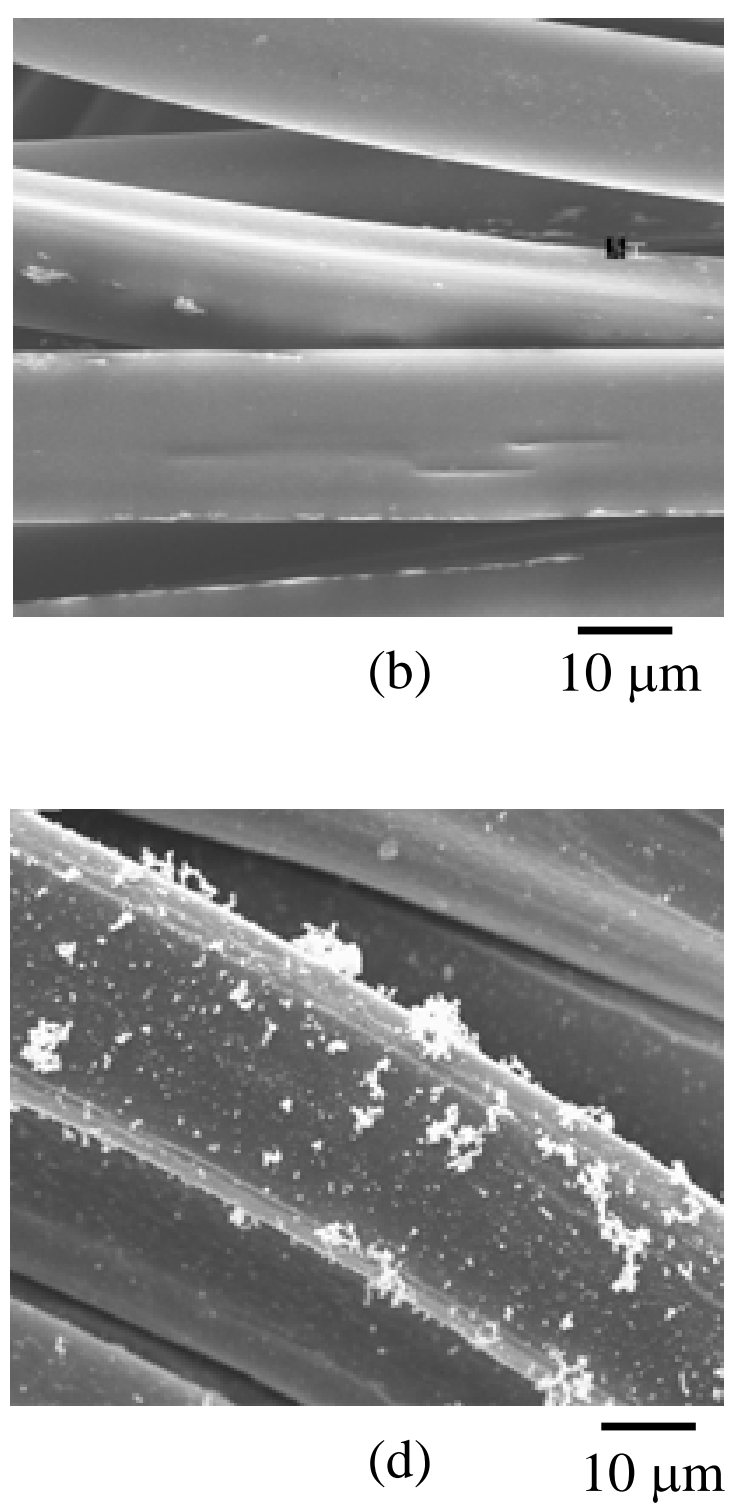

Figure 4 


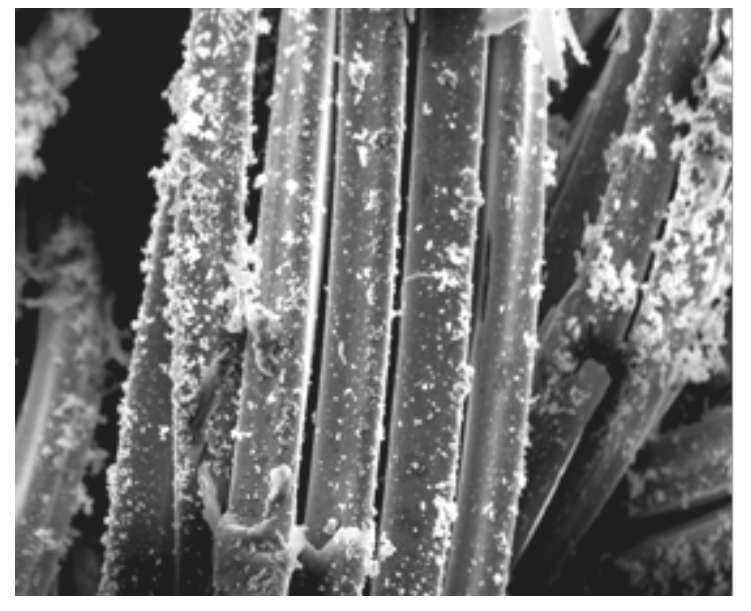

(a)

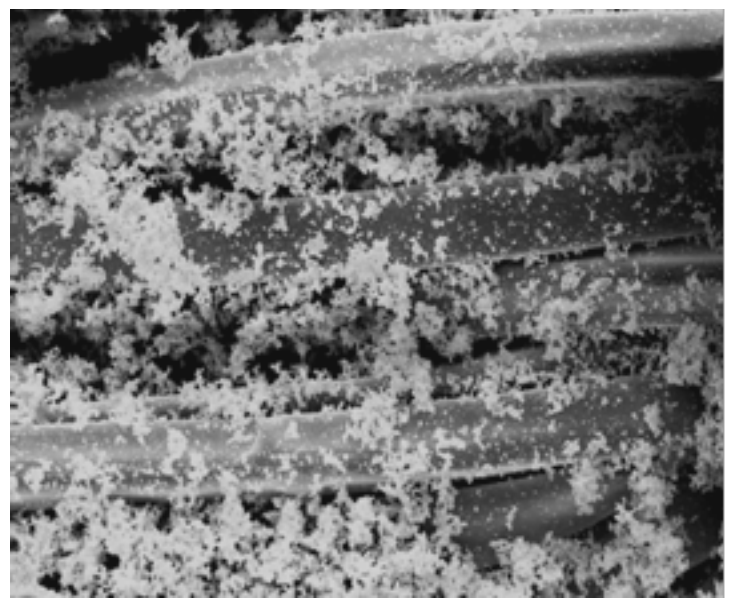

(b)

Figure 5 


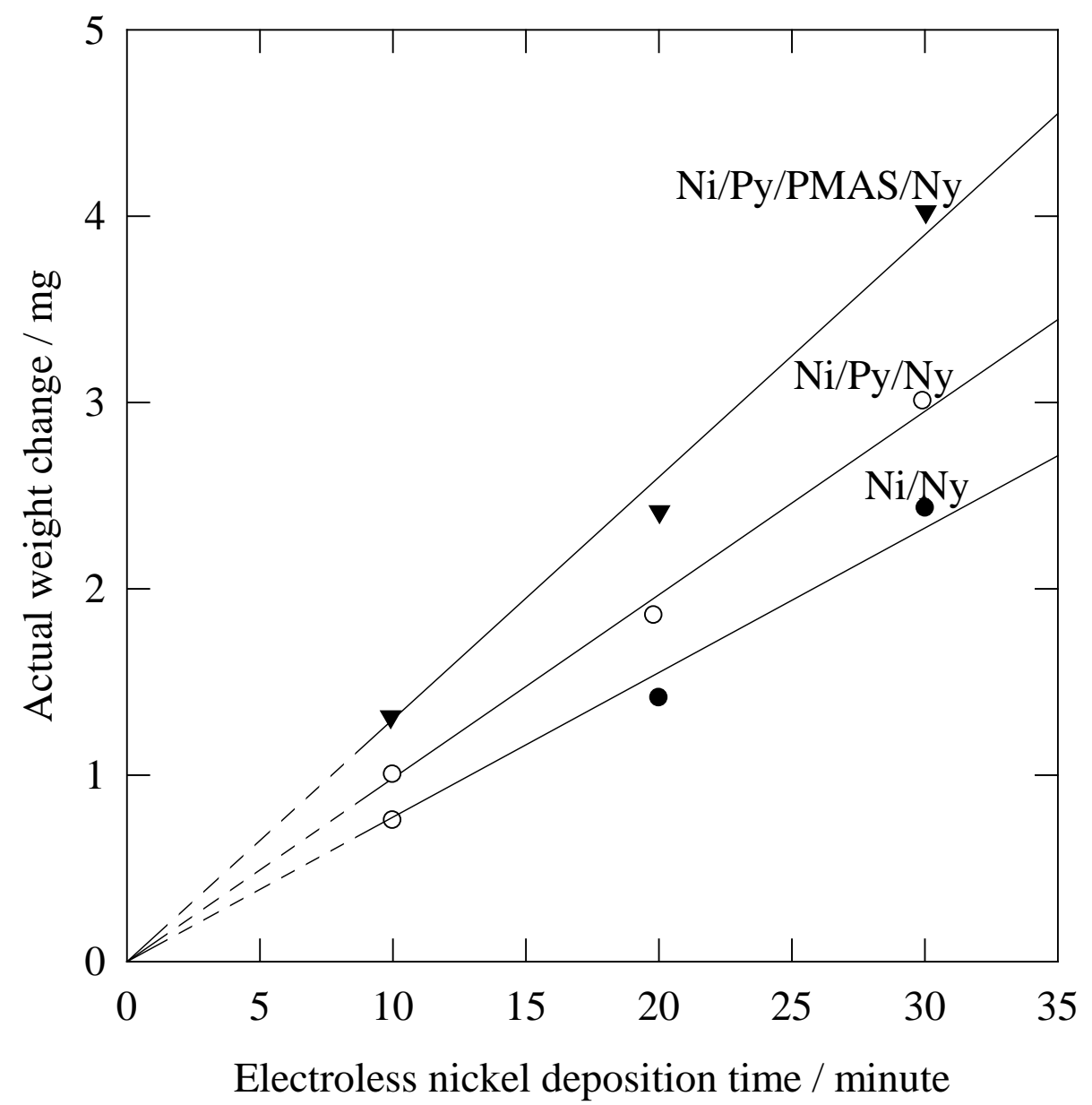

Figure 6 


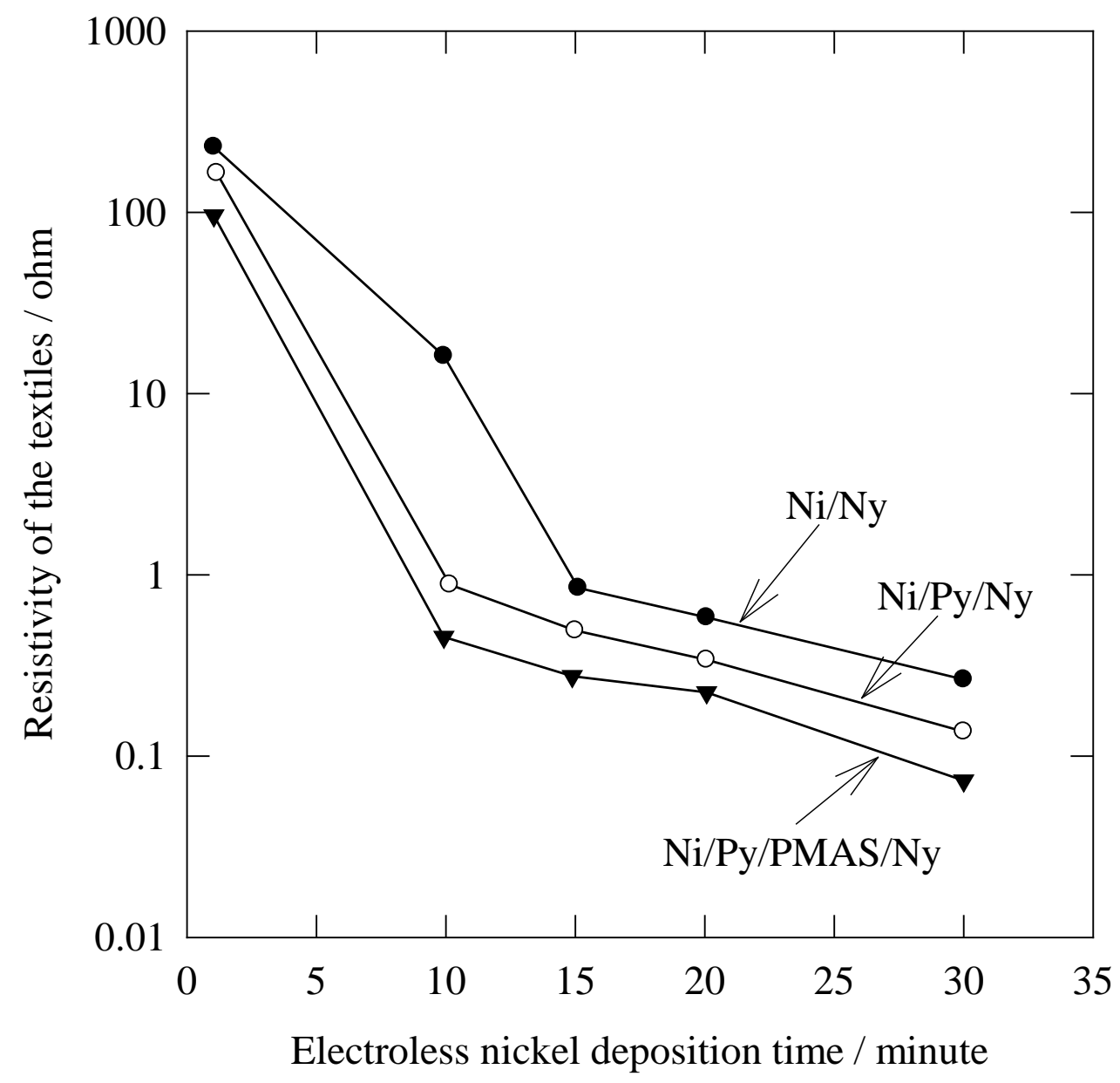

Figure 7 


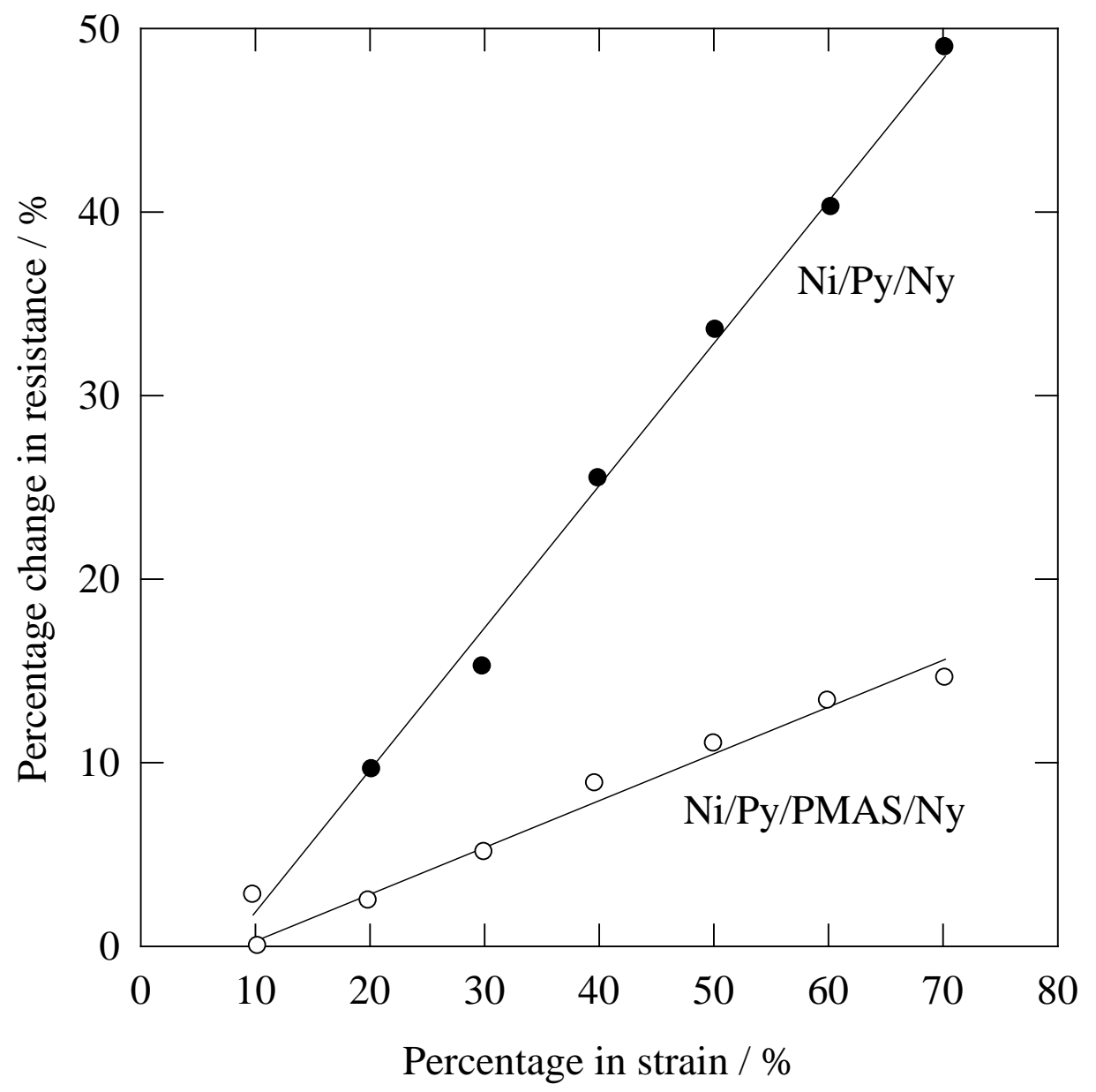

Figure 8 


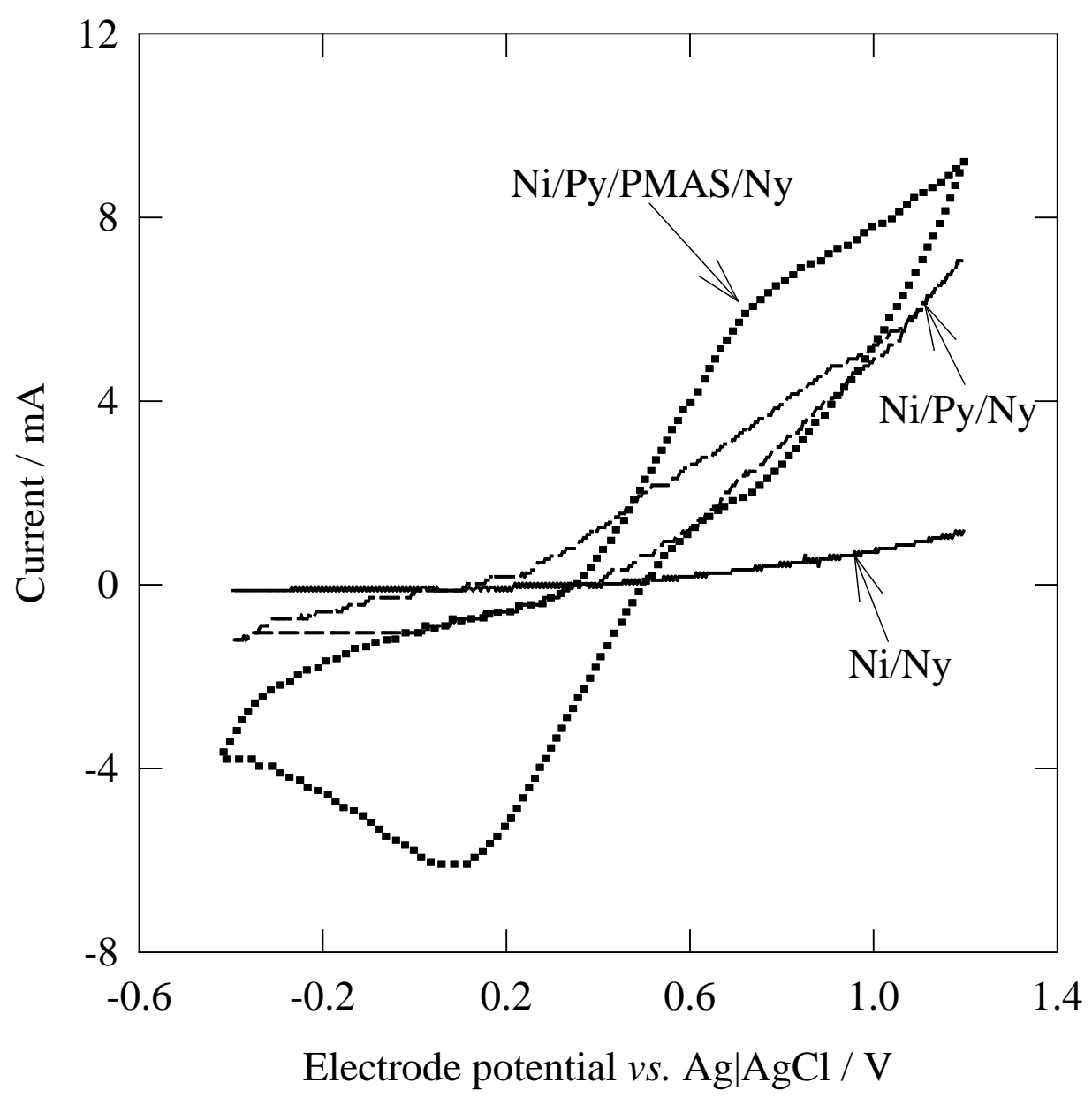

Figure 9 